\title{
Anti-PD-1 Fusion Protein AMP-224
}

National Cancer Institute

\section{Source}

National Cancer Institute. Anti-PD-1 Fusion Protein AMP-224. NCI Thesaurus. Code C97039.

A recombinant B7-DC Fc-fusion protein composed of the extracellular domain of the PD1 ligand programmed cell death ligand 2 (PD-L2, B7-DC) and the Fc region of human immunog lobulin (Ig) G1, with potential immune checkpoint inhibitory and antineoplastic activities. Anti-PD-1 fusion protein AMP-224 specifically binds to PD-1 on chronically stimulated $\mathrm{T}$-cells and reduces their proliferation. This may restore immune function and may result in the activation of cytotoxic T-cells and cell-mediated immune responses against tumor cells. PD-1, a transmembrane protein of Ig superfamily and inhibitor receptor expressed on activated $\mathrm{T}$-cells, negatively regulates $\mathrm{T}$-cell activation and effector function when activated by its ligands, and plays an important role in tumor evasion from host immunity. AMP-224 does not bind normal activated T-cells. 